\title{
Swelling Behavior, Interaction, and Electrostatic Properties of Chitosan/Alginate Dialdehyde Multilayer Films with Different Outermost Layer
}

Huang, Junhao; Moghaddam, Saeed Zajforoushan; Maroni, Plinio; Thormann, Esben

Published in:

Langmuir

Link to article, DOI:

10.1021/acs.langmuir.0c00330

Publication date:

2020

Document Version

Peer reviewed version

Link back to DTU Orbit

Citation (APA):

Huang, J., Moghaddam, S. Z., Maroni, P., \& Thormann, E. (2020). Swelling Behavior, Interaction, and Electrostatic Properties of Chitosan/Alginate Dialdehyde Multilayer Films with Different Outermost Layer. Langmuir, 36(14), 3782-3791. https://doi.org/10.1021/acs.langmuir.0c00330

\section{General rights}

Copyright and moral rights for the publications made accessible in the public portal are retained by the authors and/or other copyright owners and it is a condition of accessing publications that users recognise and abide by the legal requirements associated with these rights.

- Users may download and print one copy of any publication from the public portal for the purpose of private study or research.

- You may not further distribute the material or use it for any profit-making activity or commercial gain

- You may freely distribute the URL identifying the publication in the public portal 


\title{
Swelling behavior, interaction, and electrostatic properties of chitosan/alginate dialdehyde multilayer films with different outermost layer
}

\author{
Junhao Huang, ${ }^{\dagger}$ Saeed Zajforoushan Moghaddam, ${ }^{\dagger}$ Plinio Maroni, ${ }^{\ddagger}$ Esben Thormannn ${ }^{*}, \dagger$ \\ †Department of Chemistry, Technical University of Denmark, 2800 Kgs. Lyngby, Denmark \\ ‡Department of Inorganic and Analytical Chemistry, University of Geneva, Sciences II, 30 Quai \\ Ernest-Ansermet, 1205 Geneva, Switzerland
}

\begin{abstract}
In this study, self-cross-linked chitosan/alginate dialdehyde multilayer films, capped with either alginate dialdehyde (6 layers) or chitosan (7 layers), are fabricated using the layer-by-layer method. The disruption of the electrostatic equilibrium when exposing the fabricated layers to acidic and alkaline conditions causes swelling within the film and independently in the outermost layer, showing dependence on the ionic strength. Spectroscopic ellipsometry and quartz crystal microbalance with dissipation monitoring are employed to examine the swelling behavior. Atomic force microscopy colloidal probe measurements are conducted to assess the surface forces between the multilayer films at different $\mathrm{pH}$ and ionic strengths. Finally, the electrostatic properties of the multilayer films are examined at different $\mathrm{pH}$ and ionic strengths using zeta potential measurements. The results suggest that stimuli-responsiveness and overall swelling behavior of the polysaccharide multilayer films significantly depend on the outermost layer, an effect that should expectedly become more pronounced the thinner the film becomes.
\end{abstract}

Keywords: chitosan, alginate dialdehyde, polyelectrolyte multilayer, ionic strength, swelling, $\mathrm{pH}-$ responsiveness 


\section{Introduction}

Multilayer films of chitosan (CHI) and alginate (ALG) are of great interest due to their biocompatibility, biodegradability, tunable structural properties, and stimuli-responsiveness. ${ }^{1}$ In addition, there are plenty of possibilities to chemically modify these polysaccharides, not only to introduce electrostatic charges but also to accommodate desired functional groups. ${ }^{2-5}$ Herein, ALG is oxidized using sodium metaperiodate to produce aldehyde groups, which can form covalent imine bonds with the amine groups of CHI through a Schiff base reaction. ${ }^{6-8}$ Accordingly, oxidized alginate, also known as alginate dialdehyde (ADA), can self-cross-link with CHI. ${ }^{9-11}$ Therefore, while the electrostatic attraction between the polyions mostly controls the layer-by-layer (LbL) assembly of the multilayer film, the aldehyde groups allow for instantaneous chemical cross-linking. This approach then constitutes an alternative to the use of typical post-cross-linkers, e.g., glutaraldehyde, ethylenediaminetetraacetic acid, and genipin. ${ }^{12-15}$ Self-cross-linked $\mathrm{CHI} / \mathrm{ADA}$ multilayer films are responsive to variations in the $\mathrm{pH}$ of the medium in terms of reversible swelling/collapse; nevertheless, without disintegration of the coating. ${ }^{16}$ For this reason, $\mathrm{CHI} / \mathrm{ADA}$ multilayer films are considered as promising coating materials for biomedical applications such as targeted drug delivery and tissue engineering. ${ }^{17-24}$

Regarding the structure, a polyelectrolyte multilayer film is generally divided into two distinct regions. ${ }^{25,26}$ The internal part of the film consists of complexes of oppositely charged polyions, which comprise interpenetrated polymer chains with approximately 1:1 charge stoichiometry (intrinsic charge compensation). On the other hand, the outermost layer partly pairs with the beneath layer, meantime the excess unpaired segments create a surface charge reversal. As a result, the counterions adsorb to the outer layer (extrinsic charge compensation) to maintain the overall charge neutrality of the film. Since the degree of ionization of weak polyelectrolytes depends on the $\mathrm{pH}$ of the media, the corresponding multilayer films typically demonstrate $\mathrm{pH}$-responsiveness as well. ${ }^{27-31}$ Changing the $\mathrm{pH}$ 
perturbs the charge-neutrality condition, which then creates excess positive or negative charges within the film that promote electrostatic repulsions and an osmotic effect due to the adsorption of the counterions. ${ }^{32}$ The produced charge imbalance can lead to swelling, irreversible structural changes, and ultimately dissolution of the film. Chemical cross-linking of the film can preserve the film integrity as the film swells until a balance between the favorable osmotic effect and the unfavorable entropy of stretching of the chains between the cross-link points is reached. ${ }^{33,34}$ The ionic strength, on the other hand, can impose multiple effects on the polyelectrolyte systems and multilayer films. ${ }^{35}$ As the most general effect, increasing the ionic strength screens the intra-chain electrostatic interactions leading to a less extended chain conformation. ${ }^{36}$ Such an effect is plausible for the outermost part of the multilayer films where dilute unpaired polyelectrolyte segments exist. The effect of ionic strength on the inner layer structure can be more complex depending on the composition of the multilayer, the interactions between the components, and the local steric crowding and electrostatic forces. ${ }^{37-42}$

This work investigates how $\mathrm{pH}$ and ionic strength affect the swelling behavior, interaction, and electrostatic properties of CHI/ADA multilayer films. To do so, multilayer films comprising 6 layers (capped with $\mathrm{ADA}$ ) and 7 layers (capped with $\mathrm{CHI}$ ) are fabricated. Accordingly, we examine how changing the $\mathrm{pH}$ and ionic strength affect the multilayer properties depending on if the outermost layer is CHI or ADA. Quartz crystal microbalance with dissipation monitoring (QCM-D) is employed to monitor the growth of the multilayer films, as well as assessing the swelling behavior in response to variations in $\mathrm{pH}$ at different ionic strengths. Spectroscopic ellipsometry is used to assess the optical thickness of the films at different conditions. Next, atomic force microscopy (AFM) colloidal probe measurements are conducted to investigate the interactions between symmetric multilayers (6 layers against 6 layers and 7 layers against 7 layers) at different $\mathrm{pH}$ and ionic strengths. Finally, zeta potential measurements are performed to investigate the electrostatic properties of the multilayer films at different conditions. The results reveal that stimuli-responsiveness, swelling behavior, interaction, and 
electrostatic properties of $\mathrm{CHI} / \mathrm{ADA}$ multilayer films strongly depend on if the outermost layer is $\mathrm{CHI}$ or ADA.

\section{Experimental section}

\section{Materials}

Sodium alginate $\left(\mathrm{NaAlg}\right.$, viscosity $\geq 2000 \mathrm{cP}$ for $2 \%$ solution in water at $25^{\circ} \mathrm{C}, \mathrm{M} / \mathrm{G}$ ratio of 1.56 ), chitosan (CHI, degree of deacetylation of $75-85 \%$, viscosity $20-300 \mathrm{cP}$ for $1 \%$ solution in acetic acid at $25{ }^{\circ} \mathrm{C}$ ), 3-glycidoxypropyltrimethoxysilane (GPS, $\geq 98 \%$ ), sodium hydroxide $(\mathrm{NaOH}, \geq 97 \%$ ), dibasic sodium phosphate $\left(\mathrm{Na}_{2} \mathrm{HPO}_{3}, \geq 99 \%\right)$, sodium dihydrogen phosphate $\left(\mathrm{NaH}_{2} \mathrm{PO}_{3}, \geq 99 \%\right)$, sodium cyanoborohydride $\left(\mathrm{NaBH}_{3} \mathrm{CN}, 95 \%\right)$, sodium metaperiodate $\left(\mathrm{NaIO}_{4}, \geq 99.5 \%\right)$, sodium chloride $(\mathrm{NaCl}, \geq 99 \%$ ), and ethylene glycol (99.8\%) were all purchased from Sigma-Aldrich. Degassed ultrapure water (Sartorius, Arium Pro) with a resistivity of $18.2 \mathrm{M} \Omega . \mathrm{cm}$ was used to prepare all the buffers and polymer solutions. Alginate dialdehyde (ADA) was prepared according to the previously reported procedure. ${ }^{16}$ Briefly, $1 \mathrm{w} / \mathrm{w} \% \mathrm{NaAlg}$ solution was prepared in ultrapure water, followed by the addition of $\mathrm{NaIO}_{4}(20 \mathrm{~mol} \%$ relative to the number of repetitive units of sodium alginate) and stirring in the dark for $24 \mathrm{~h}$. The oxidation reaction was then quenched by the addition of $2 \mathrm{ml}$ ethylene glycol under stirring for $0.5 \mathrm{~h}$. ADA was first precipitated by adding ethanol and then was purified by dialysis against ultrapure water for 3 days, followed by lyophilization.

\section{Quartz crystal microbalance with dissipation monitoring (QCM-D)}

QCM-D (Q-Sense E1, Biolin Scientific, Gothenburg, Sweden) measurements were conducted to monitor the LbL assembly and investigate the swelling behavior of the multilayer films. Silicasputtered sensors (QSX 335, Biolin Scientific) were first rinsed with acetone, ethanol, washed with a copious amount of ultrapure water, and dried using compressed air. The sensors were then plasmatreated (PDC-32G plasma cleaner, Harrick Plasma, medium power, using air with a vapor pressure of 
0.5 Torr) for $5 \mathrm{~min}$ to remove any organic contaminants. The sensors were then immersed in $18 \mathrm{v} / \mathrm{v}$ $\%$ GPS/acetone solution for $22 \mathrm{~h}$, followed by thorough rinsing with acetone. ${ }^{43}$ The GPS-modified sensors were then immersed in CHI solution (100 ppm in $15 \mathrm{mM}$ PBS at pH 6) for 40 mins followed by rinsing with ultrapure water. ${ }^{44}$ By doing so, the first layer of $\mathrm{CHI}$ is covalently grafted to the epoxide-modified silica substrate. The sensor was mounted in the QCM-D instrument module, and the flow cell was loaded with $15 \mathrm{mM}$ PBS at pH 6 using a $0.15 \mathrm{ml} \mathrm{min}^{-1}$ flow rate. After obtaining a stable baseline, the ADA solution (200 ppm in $15 \mathrm{mM}$ PBS at pH 6) was loaded into the chamber for 40 min followed by 20 min rinsing with the PBS solution. A similar procedure was repeated using the CHI solution (100 ppm in $15 \mathrm{mM}$ PBS at $\mathrm{pH}$ 6). Following these sequential steps, multilayer films capped with ADA (6 layers) and $\mathrm{CHI}$ (7 layers) were fabricated. A reduction reaction using $\mathrm{NaBH}_{3} \mathrm{CN}$ was then conducted to transform the dynamic imine bonds to permanent amine bonds. ${ }^{45}$ To do so, $\mathrm{NaBH}_{3} \mathrm{CN}$ solution (30 mM in $15 \mathrm{mM}$ PBS at pH 6) was loaded into the chamber for $1 \mathrm{~h}$, followed by $1.5 \mathrm{~h}$ rinsing with PBS buffer.

Next, the effect of changing $\mathrm{pH}$ at different salt concentrations was investigated. The initial baseline was obtained in $1 \mathrm{mM} \mathrm{NaCl}$ at $\mathrm{pH}$ 6. Then, 3 consecutive $\mathrm{pH}$ cycles between $\mathrm{pH} 6$ and $\mathrm{pH} 3$ were performed, followed by three $\mathrm{pH}$ cycles between $\mathrm{pH} 6$ and $\mathrm{pH}$ 9. A new baseline was then obtained in $10 \mathrm{mM} \mathrm{NaCl}$ at $\mathrm{pH}$ 6, and the $\mathrm{pH}$ cycles were performed at this ionic strength. A similar procedure was employed for the $100 \mathrm{mM} \mathrm{NaCl}$ solutions. A stabilization time of $40 \mathrm{~min}$ was given between each step (in all cases, before changing to a new solution, the frequency and dissipation variations over 10 min were less than $0.2 \mathrm{~Hz}$ and $0.2\left(\times 10^{6}\right)$, respectively). Note: adjusting the $\mathrm{pH}$ to 3 and 9 requires 1 $\mathrm{mM} \mathrm{HCl}$ and $0.01 \mathrm{mM} \mathrm{NaOH}$, respectively. Therefore, for the solutions with $\mathrm{pH} 3$, ultrapure water, $9 \mathrm{mM}$, and $99 \mathrm{mM} \mathrm{NaCl}$ solutions were used to obtain overall ionic strengths of $1 \mathrm{mM}, 10 \mathrm{mM}$, and $100 \mathrm{mM}$, respectively. 


\section{Preparation of multilayer films on silicon wafer/colloidal probe}

Thermal oxide silicon wafer (Wafernet Inc., San Jose, CA) was used to prepare the samples for the spectroscopic ellipsometry, AFM, and zeta potential experiments. The wafers were first rinsed with acetone, ethanol, and ultrapure water, then dried with compressed air, and finally, plasma cleaned (PDC-32G plasma cleaner, Harrick Plasma, medium power, using air with a vapor pressure of 0.5 Torr). The wafers were then immersed in $18 \mathrm{v} / \mathrm{v} \% \mathrm{GPS} /$ acetone solution for $22 \mathrm{~h}$, followed by rinsing with acetone. A similar procedure was performed to clean and functionalize the AFM colloidal probe. Silica particles with a diameter of around $7 \mu \mathrm{m}$ (Bangs Laboratories Inc., USA) were repeatedly rinsed with acetone and ultrapure water by centrifugation, immersed in the $18 \mathrm{v} / \mathrm{v} \% \mathrm{GPS} /$ acetone solution for $22 \mathrm{~h}$, and then rinsed with acetone by centrifugation. A GPS-modified silica particle was glued to the end of a tipless rectangular cantilever (CSC37/Cr-Au, Mikromasch) using a small amount of a two-component epoxy adhesive (Araldite ${ }^{\circledR}$ Rapid). After treatment with GPS, the silica wafers and the AFM colloidal probe cantilevers were immersed in the CHI solution (100 ppm in $15 \mathrm{mM}$ PBS at $\mathrm{pH}$ 6) for 40 mins to covalently graft the first $\mathrm{CHI}$ layer to the substrate. After the modification,

they were put into a custom-made flow cell using a flow rate of $0.5 \mathrm{ml} \mathrm{min}{ }^{-1}$. A rinsing step using 15 $\mathrm{mM}$ PBS at $\mathrm{pH} 6$ was conducted for $1 \mathrm{~h}$ to remove the unbound CHI. Herein, we chose an approximate exchange ratio (loaded liquid/flow cell volume) similar to in the QCM-D experiment, to prepare the multilayer films on the silica wafers and the colloidal probe. To conduct the LbL assembly, the ADA (200 ppm in $15 \mathrm{mM}$ PBS at pH 6) and CHI (100 ppm in $15 \mathrm{mM}$ PBS at pH 6) solutions were loaded into the flow cell for $1 \mathrm{~h}$ with $1.5 \mathrm{~h}$ rinsing by $15 \mathrm{mM}$ PBS at $\mathrm{pH} 6$ in between. Following this procedure, multilayer films capped with $\mathrm{ADA}$ (6 layers) and $\mathrm{CHI}$ (7 layers) were fabricated on the silica wafers and the AFM colloidal probe. A reduction reaction was then conducted by loading $\mathrm{NaBH}_{3} \mathrm{CN}$ solution (30 mM in $15 \mathrm{mM}$ PBS at $\mathrm{pH}$ 6) for $1 \mathrm{~h}$ followed by $1.5 \mathrm{~h}$ rinsing with buffer. 


\section{Spectroscopic ellipsometry}

Spectroscopic ellipsometry measurements (M-2000U, J.A. Woollam Co., Inc.) were carried out using the standard liquid cell of the instrument ( $5 \mathrm{~mL}$ Heated Liquid Cell ${ }^{\mathrm{TM}}$ ). The ellipsometric $\Psi$ (represents the angle calculated from the amplitude ratio of $\mathrm{p}$ - and s-polarizations) and $\Delta$ (represents the phase shift between the p- and s-polarizations) were collected in the wavelength range of $245-1000 \mathrm{~nm}$ at an angle of incidence of $75^{\circ}$. The measurements were first performed on multilayer films with 6 and 7 layers on the silicon wafer; however, the optical thicknesses were relatively small, and the differences were insignificant (strong correlation between the model parameters). Hence, relatively thicker multilayer films with 14 (capped with ADA) and 15 (capped with $\mathrm{CHI}$ ) layers were prepared and the optical thicknesses were estimated. The films were firstly given an equilibrium time of $40 \mathrm{~min}$ in $1 \mathrm{mM}$

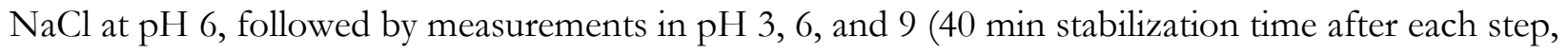
the thickness variations over 10 min were less than $0.1 \mathrm{~nm}$ before changing to a new solution). A similar procedure was used for the measurements in 10 and $100 \mathrm{mM}$ solutions. The optical behavior of the multilayer films was modeled using the empirical Cauchy relation $\left(n(\lambda)=A+B / \lambda^{2}\right)$. The optical constants of pure water at $25{ }^{\circ} \mathrm{C}$ (from the software library) were used for all solutions (corrected optical constants of $100 \mathrm{mM} \mathrm{NaCl}$ were tested, but minor changes in the data were found). ${ }^{46}$ The instrument software (CompleteEASE) was used for data modeling and analysis.

\section{AFM colloidal probe measurements}

AFM (NanoWizard 3 AFM, JPK Instruments AG, Berlin, Germany) colloidal probe measurements were performed to investigate the surface forces between the multilayer films. The accurate spring constant of the unloaded cantilevers (CSC37/Cr-Au, Mikromasch) was determined by the Sader method. ${ }^{47}$ The sensitivity of the cantilevers (loaded, before coating) was obtained by performing force measurements against a bare silica wafer (Supporting Information, Figure S1). A similar procedure as 
that of the ellipsometry experiment was used herein (40 min stabilization time). A constant approach and retraction speed of $400 \mathrm{~nm} \mathrm{~s}^{-1}$ was used to avoid hydrodynamic effects. ${ }^{48}$ For each condition, three randomly chosen areas $(10 \mu \mathrm{m} \times 10 \mu \mathrm{m}, 36$ points on each area) of the sample were chosen to perform the force measurements. The standard software of the instrument (JPK SPM Data Processing) was utilized to analyze the force curves.

\section{Zeta potential measurements}

Zeta potential (SurPASS, Anton Paar GmbH, Graz, Austria) measurements were conducted to examine the electrostatic properties of the multilayer films. Two silica substrates $(20 \mathrm{~mm} \times 10 \mathrm{~mm})$ were mounted into the instrument flow cell separated by a $100 \pm 5 \mu \mathrm{m}$ capillary channel. The solutions were pumped through the capillary channel between the two samples, producing a linearly increasing measurement pressure (rinsing time of $180 \mathrm{~s}$, target pressure of $400 \mathrm{mbar}$ ). Zeta potential was calculated using the Hermann von Helmholtz equation for planar solids. ${ }^{49}$ The measurements were conducted in the order of increasing ionic strength and $\mathrm{pH}$ (for a given ionic strength, the $\mathrm{pH}$ of the solution was increased from 3 to 9 using an auto-titration system). To ensure the reliability of the data, the experiments were repeated twice.

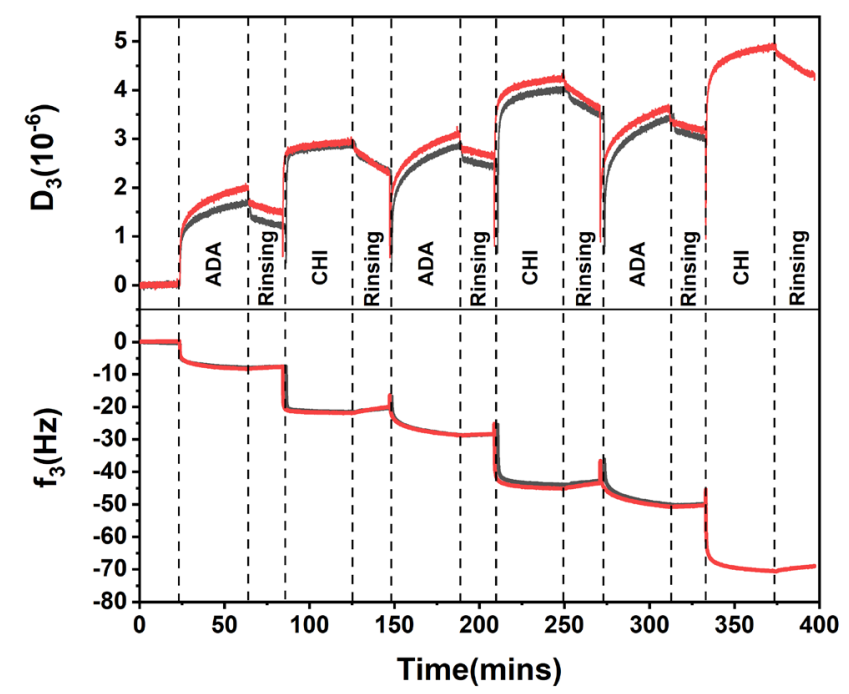


Figure 1 QCM-D data for layer-by-layer (LbL) assembly of the multilayer films; frequency (f) and dissipation (D) shifts for $3^{\text {rd }}$ overtone as a function of time for multilayer films capped with ADA (6 layers, dark gray line) and CHI (7 layers, red line). The two separate figures nearly superimpose, affirming the reproducibility of the LbL assembly and film growth.

\section{Results}

\section{LbL assembly}

Figure 1 presents the frequency (f) and dissipation (D) shifts resulting from the LbL assembly of the multilayer films. The multilayer film capped with ADA (dark gray line) comprises 6 deposited layers and the multilayer film capped with CHI (red line) consists of 7 deposited layers. It has to be noted that, in both cases, the first deposited CHI layer is covalently attached to the GPS-modified silica surface, which can ensure the stability of the films. The sequential deposition of the polyions is characterized by a continuous decrease in $\mathrm{f}$ and increase in $\mathrm{D}$. The former implies enhanced coupled mass, i.e., polymer film with hydrodynamic water content, while the latter represents the enhanced viscoelastic nature of the adhered film. A closer inspection of the data reveals that the deposition of CHI leads to a decrement in $\mathrm{f}(\sim 16 \mathrm{~Hz})$ that is nearly twice as large compared to the deposition of ADA $(\sim 8 \mathrm{~Hz})$, which suggests non-symmetrical adsorption of the polyions. A similar trend is found for $\mathrm{D}$ where deposition of $\mathrm{CHI}$ is characterized by relatively larger shifts compared to the deposition of ADA. We suggest this behavior originates from the difference in the charge fractions of CHI and $\mathrm{ADA}$. The $\mathrm{p} K_{a}$ of a free (non-grafted) $\mathrm{CHI}$ chain in solution is $\sim 6.0-6.5$, and the $\mathrm{p} K_{a}$ of an isolated ADA chain in solution is $~ 3.0-3.5 .^{50,51}$ Therefore, at $\mathrm{pH} 6$ where the LbL deposition is performed, one can assume that the $\mathrm{CHI}$ chains possess a relatively low charge fraction (in the vicinity of $\mathrm{p} K_{a}$ ), whereas the ADA chains will possess a relatively high charge fraction (well above $\mathrm{p} K_{a}$ ). Therefore, more $\mathrm{CHI}$ chains need to adsorb for a given amount of adsorbed ADA to fulfill the charge neutrality condition, which may explain the larger shifts when $\mathrm{CHI}$ is deposited. 


\section{Swelling behavior: spectroscopic ellipsometry}

We herein consider that $\mathrm{CHI} / \mathrm{ADA}$ multilayer films consist of two regions with distinct conformation and electrostatic properties. The internal zone comprises entangled $\mathrm{CHI}$ and ADA chains within intrinsically compensated complexes. At pH 6 where the LbL assembly is conducted, the inner part of the $\mathrm{CHI} / \mathrm{ADA}$ multilayer should be found in a nearly charge-neutral state. Changing the $\mathrm{pH}$ produces a charge imbalance in the inner part that can give rise to film swelling. Based on the approximate $\mathrm{p} K_{a}$ values, at $\mathrm{pH} 6, \mathrm{CHI}$ is expected to be partially charged, whereas ADA is more strongly charged. By increasing the $\mathrm{pH}$ from 6 to 9, $\mathrm{CHI}$ should become almost uncharged, whereas ADA becomes further charged, which together produce a net negative charge within the film. The negative charge promotes adsorption of $\mathrm{Na}^{+}$counterions to the film and the resultant osmotic effect should lead to swelling of the inner part. Contrarily, by decreasing the $\mathrm{pH}$ from 6 to 3, CHI becomes highly charged, whereas ADA should be found in a partially charged state, which together lead to a net positive charge within the film, adsorption of $\mathrm{Cl}^{-}$counterions, and hence osmotic swelling of the inner part. 

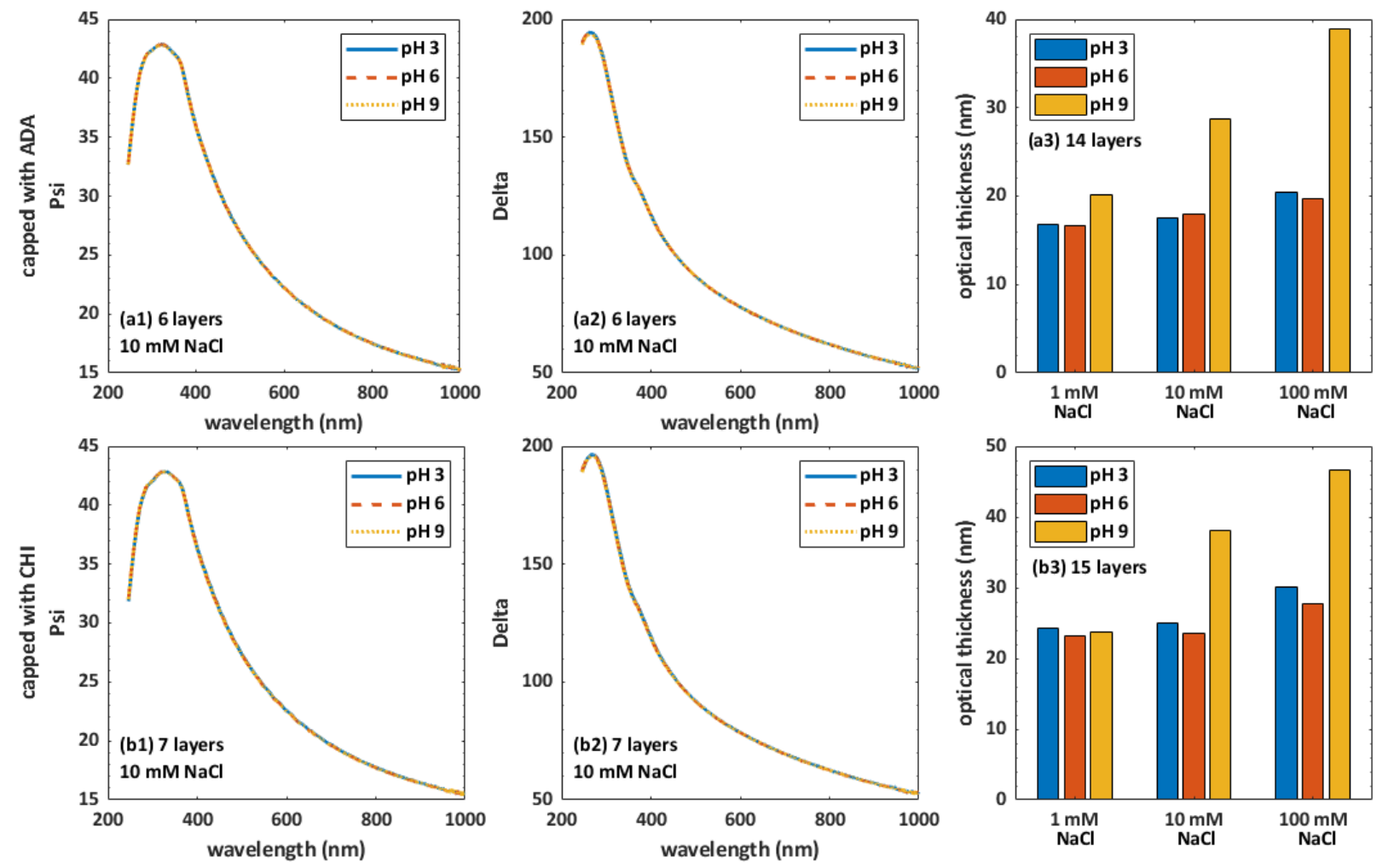

Figure 2 Ellipsometry data for the CHI/ADA multilayer films capped with ADA (top row, panel a) or CHI (bottom row, panel b). $\Psi$ (a1) and $\Delta$ (a2) spectra for the multilayer film with 6 layers in $10 \mathrm{mM} \mathrm{NaCl}$ at different $\mathrm{pH}$ values, (a3) estimated optical thickness (standard deviation of the modeled thickness values $\leq 0.25 \mathrm{~nm}$ ) of the multilayer film with 14 layers at different $\mathrm{pH}$ and ionic strengths. $\Psi$ (b1) and $\Delta$ (b2) spectra for the multilayer film with 7 layers in $10 \mathrm{mM} \mathrm{NaCl}$ at different $\mathrm{pH}$ values, (b3) estimated optical thickness (standard deviation of the modeled thickness values $\leq 0.25 \mathrm{~nm}$ ) of the multilayer film with 15 layers at different $\mathrm{pH}$ and ionic strengths.

To check the effect of $\mathrm{pH}$ and ionic strength on the swelling behavior of the inner part of the film, spectroscopic ellipsometry experiments are performed. Ellipsometry is an optical method that estimates the film thickness based on the difference in the refractive index of the medium and the hydrated polymer film. ${ }^{52,53}$ Since the outer part of the film consists mostly of dilute dangling chains, the optical properties of this zone are relatively close to that of water. Hence, ellipsometry, in general, is relatively more sensitive to the dense (polymer-rich) inner part of the film. 
Figure 2 summarizes the ellipsometry data for the multilayer films at different $\mathrm{pH}$ and ionic strengths (detailed modeling data and estimated refractive indices of the films at different conditions are provided in the Supporting Information, Figure S2-S4). It is evident that $\Psi$ and $\Delta$ spectra of the multilayer films with 6 (Figure 2(a1), (a2)) and 7 (Figure 2(b1), (b2)) layers almost superimpose and do not show significant dependence on $\mathrm{pH}$ and ionic strength. The modeling of the data suggests optical thicknesses $\sim 3-5 \mathrm{~nm}$ in all cases. However, a large degree of correlation between the free parameters of the optical model is found, which is a common challenge when studying relatively thin polymer films ( $\lesssim 10 \mathrm{~nm}$ ) using spectroscopic ellipsometry. To address this issue, multilayer films having 14 (capped with ADA, Figure 2(a3)) and 15 (capped with CHI, Figure2(b3)) layers are prepared and examined. As a general observation, changing the $\mathrm{pH}$ from 6 to 9 leads to an increment in the optical thickness, whereas changing the $\mathrm{pH}$ from 6 to 3 has quite a minor effect on the optical thickness. Thus, the positive charge imbalance when $\mathrm{pH}$ is changed from 6 to 3 is apparently less pronounced than the negative charge imbalance when $\mathrm{pH}$ is changed from 6 to 9 , which can be attributed to the different amounts of $\mathrm{CHI}$ and ADA in the film, different charge fractions of $\mathrm{CHI}$ and ADA when fully ionized, proximity to the corresponding $\mathrm{p} K_{a}$ values, and conformational restrictions due to crosslinking. As another general observation, the optical thickness enhances with an increase in the ionic strength, an effect that is notably more pronounced at $\mathrm{pH}$ 9. Such swelling behavior may be explained based on the local steric crowding and electrostatic forces reported for dense weak polyelectrolyte brushes. ${ }^{40,41}$ According to the ellipsometry results, we can thus consider that the dense inner part of the multilayer films notably swells when $\mathrm{pH}$ is increased from 6 to 9 , whereas minor swelling occurs between pH 6 and 3. For relatively thin films, including CHI/ADA films with 6 and 7 layers, these variations in the internal part thickness are expectedly less pronounced. 
The outer part of the multilayer film can be considered as less entangled chains with more degrees of freedom that are partly paired with the beneath layer (intrinsic compensation) and partly compensated with counterions in the solution (extrinsic compensation). Changing the $\mathrm{pH}$ should affect the charge fraction and conformation of the outer layer depending on the corresponding $\mathrm{p} K_{a}$. When the multilayer film is capped with ADA, the outer layer should be found in collapsed, partly swollen, and highly swollen states at $\mathrm{pH} 3,6$, and 9, respectively. An opposite trend is expected when the multilayer film is capped with CHI, i.e., highly swollen, partly swollen, and collapsed outer layer at pH 3, 6, and 9 , respectively. Based on the discussed effects in the inner and outer parts, it is expected that multilayer films capped with $\mathrm{CHI}$ or ADA demonstrate two different swelling behaviors. When having ADA as the outer layer, increasing the $\mathrm{pH}$ should lead to swelling in both the inner and the outer parts of the film. Contrarily, when having $\mathrm{CHI}$ as the outer layer, increasing the $\mathrm{pH}$ should result in swelling of the inner part but the collapse of the outer part. To further test this hypothesis, QCM-D and AFM force measurements are conducted and discussed in the following sections. 

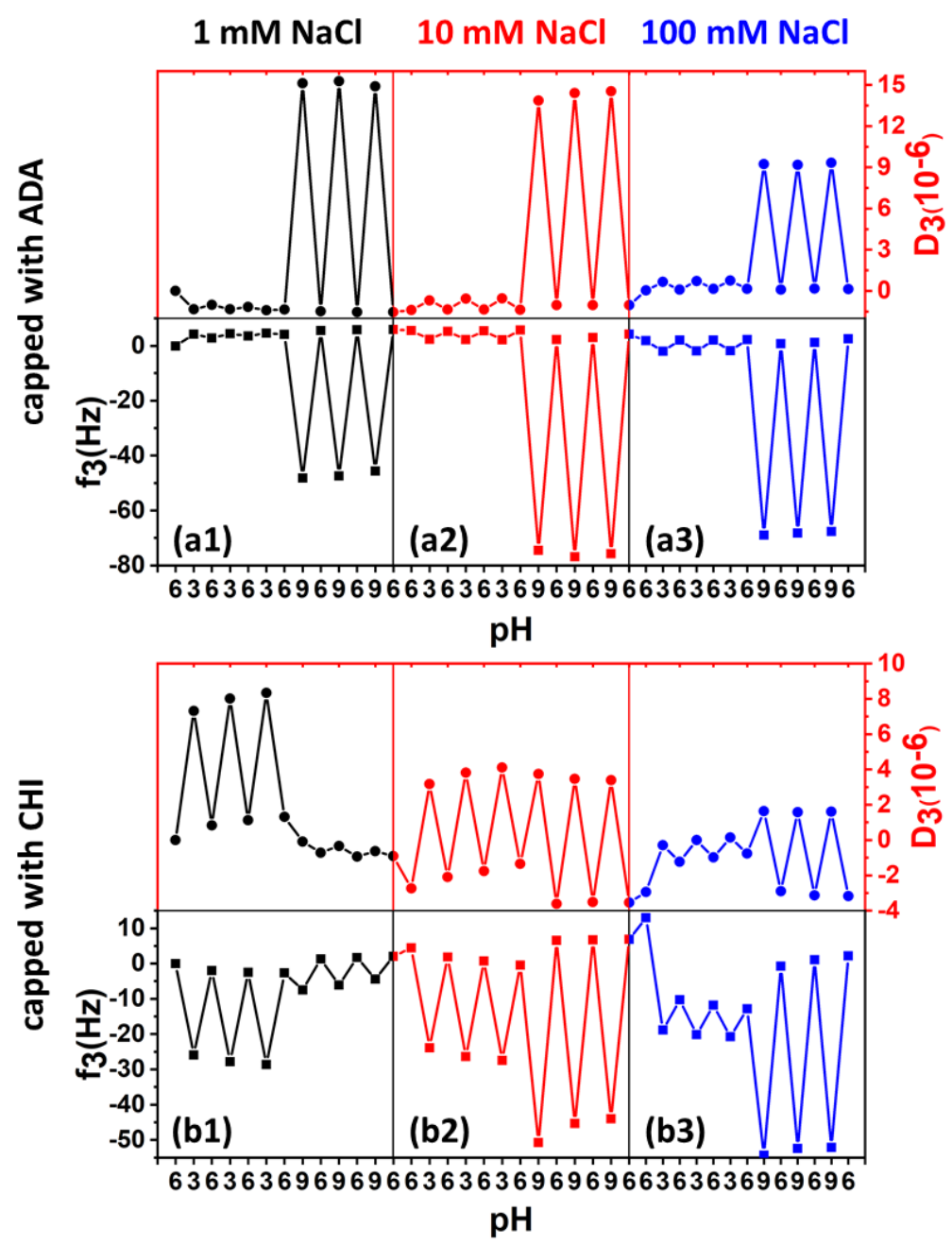

Figure 3 QCM-D data for $\mathrm{pH}$-induced swelling; frequency (f, square) and dissipation (D, circle) shifts for $\mathrm{pH}$ changes at different ionic strengths for multilayer films capped with ADA (6 layers, panel a) and CHI (7 layers, panel b).

\section{Swelling behavior: QCM-D}

Figure 3 summarizes the QCM-D swelling data of the multilayer films (6 and 7 layers) at different $\mathrm{pH}$ and ionic strengths. Regarding the multilayer film capped with ADA (Figure 3, panel a), the shifts in $\mathrm{f}$ and $\mathrm{D}$ suggest a significant swelling when the $\mathrm{pH}$ is changed from 6 to 9 . This can be attributed to swelling of the inner layer as well as swelling of the outermost ADA layer. On the other hand, decreasing the $\mathrm{pH}$ from 6 to 3 has an insignificant effect on $\mathrm{f}$ and $\mathrm{D}$, which can hint to minor structural changes and (or) counterbalancing effects. By decreasing $\mathrm{pH}$ from 6 to 3, the inner part of the film is 
expected to slightly swell (see Figure 2), whereas the outermost ADA layer should become more collapsed due to the protonation of carboxyl groups. These two minor contributions may cancel out each other. Besides, increasing the ionic strength has no significant effect on the $\mathrm{pH}$ cycle between 3 and 6. Contrarily, increasing the ionic strength has a substantial effect on the swelling behavior under the alkaline condition, i.e., increasing the ionic strength leads to reduced swelling when $\mathrm{pH}$ is changed from 6 to 9. As demonstrated in Figure 2, increasing the ionic strength leads to swelling in the inner part of the film, in particular at $\mathrm{pH}$ 9. The attenuated swelling observed in Figure 3 (panel a) then suggests a conformational collapse in the outer layer with increasing ionic strength, which could be attributed to electrostatic screening effect. We will discuss this effect further in the next section regarding the AFM force measurements.

Regarding the multilayer film capped with CHI (Figure 3, panel b), it is evident that the swelling behavior considerably differs from that of the multilayer film capped with ADA. Herein, changing $\mathrm{pH}$ from 6 to 3 is associated with relatively large shifts in $f$ and D, suggesting swelling of the multilayer. As discussed, the inner part of the film, as well as the outermost CHI layer should both swell in an acidic medium. Nevertheless, since the inner part is expected to undergo minor swelling (according to Figure 2), we suggest that the observed shifts in $\mathrm{f}$ and $\mathrm{D}$ chiefly originate from swelling in the outermost CHI layer. In addition, increasing the ionic strength leads to a weaker swelling, which could be similarly attributed to the electrostatic screening effect on the outer layer. When changing the $\mathrm{pH}$ from 6 to 9, we observe a rather complex swelling behavior with significant dependence on the ionic strength. Minor shifts in $\mathrm{f}$ and $\mathrm{D}$ are found for the lowest ionic strength. By increasing the ionic strength, the multilayer film shows $\mathrm{pH}$-responsiveness in terms of moderate $\mathrm{f}$ and $\mathrm{D}$ shifts and thus swelling. As discussed above, two opposite effects are expected for the multilayer film capped with $\mathrm{CHI}$ when $\mathrm{pH}$ is changed from 6 to 9 . On the one hand, the outer layer should collapse due to the deprotonation of amine groups on CHI. On the other hand, the inner part of the film should swell 
due to the negative charge imbalance. For the lowest ionic strength, it appears that these two opposing effects are counterbalancing each other, so minor shifts in the QCM-D data is found. However, when the ionic strength is increased, it appears that the swelling effect in the inner film becomes more dominant. Accordingly, one can speculate that increasing ionic strength has a relatively large screening effect on the outer layer, which will be further examined in the next section.

\section{Surface forces: AFM colloidal probe}

Figure 4 represents the approach force-separation curves obtained for the symmetric multilayer (6 and 7 layers) films, i.e., two films capped with ADA (left column, panel a) as well as two films capped with CHI (right column, panel b), at different $\mathrm{pH}$ and ionic strengths. First, it should be mentioned that, while the consecutive force curves obtained at the same position showed little variation between the individual force curves, the force curves collected at different lateral surface positions did show variations in the range and magnitude of the interaction. However, a clear averaged variation between different $\mathrm{pH}$ and ionic strengths exists in all cases, which exceeds the variation between individual forces curves (Supporting Information, Figure S5). Secondly, it should be considered that AFM only measures the relative distance and not the absolute distance between the surfaces. Herein, we defined the zero-separation point as the region where apparent hard-wall repulsion achieved at the highest applied force. Thus, the forces curves presented in Figure 4 can be considered as representative force curves with separation distances being relative to the highest level of compression. 

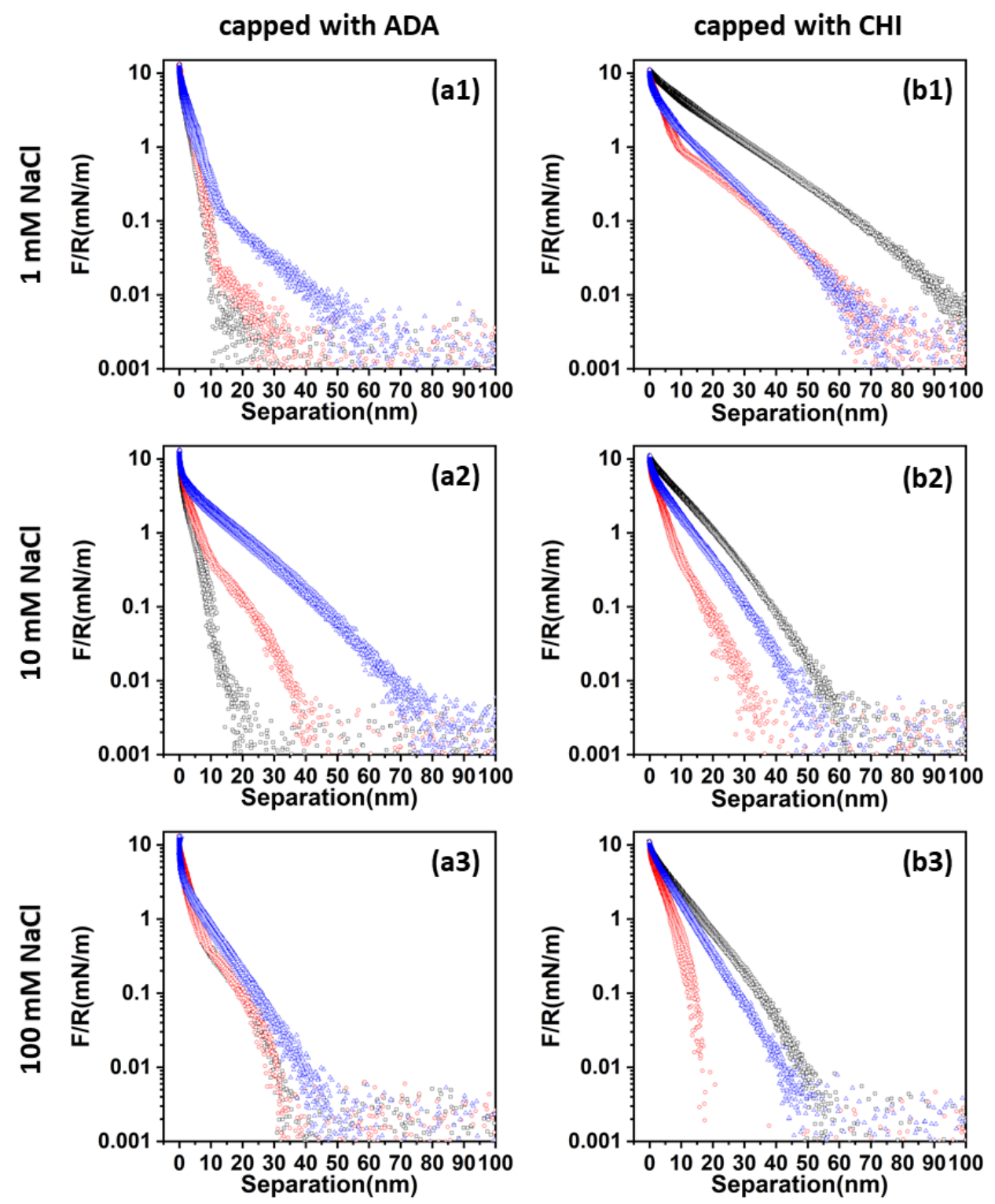

Figure 4 Approach force-distance curves between the symmetric multilayer (6 and 7 layers) films plotted on semi-log scale at different $\mathrm{pH}$ values (black squares, red circles, and blue triangles represent $\mathrm{pH} 3,6$, and 9, respectively) and ionic strengths. Panel a shows the force profiles between two multilayer films capped with ADA. Panel b provides the force profiles between two multilayer films capped with CHI. 9 representative force curves are plotted for each condition.

Before discussing the detailed observations, we note some general trends in the force curves. Regardless of the composition of the outermost layer, the ionic strength, and the $\mathrm{pH}$, we observe monotonously repulsive forces with approximate decay lengths between 10 to $100 \mathrm{~nm}$. The Debye lengths are $9.6 \mathrm{~nm}, 3.0 \mathrm{~nm}$, and $0.9 \mathrm{~nm}$ at ionic strengths of $1 \mathrm{mM}, 10 \mathrm{mM}$, and $100 \mathrm{mM}$, respectively. 
Accordingly, the measured repulsive forces are longer-ranged than double-layer forces; hence, it is safe to conclude that the variations in the force curves are related to the conformational changes discussed in Figure 2 and Figure 3.

According to Figure 4 (panel a), the force-distance curves between two multilayer films capped with ADA depend on both $\mathrm{pH}$ and ionic strength. For the lowest ionic strength (Figure 4(a1)), the force curves are similar at $\mathrm{pH} 3$ and $\mathrm{pH} 6$ (slightly longer-ranged at $\mathrm{pH}$ 6), whereas the repulsive force is considerably longer-ranged at $\mathrm{pH}$ 9. This observation is in good agreement with the structural changes discussed in relation to Figure 2 and Figure 3. Accordingly, changing pH from 6 to 3 leads to minor structural changes and probably counterbalancing effects in the inner and outer parts of the film, whereas changing $\mathrm{pH}$ from 6 to 9 produces large swelling both in the inner and outer parts of the film. Increasing the ionic strength to $10 \mathrm{mM}$ (Figure 4(a2)) seems to have a minor effect on the range of the interactions. Long-ranged repulsive forces are measured at $\mathrm{pH}$ 9, implying the highly swollen nature of the outermost ADA layer. It has to be mentioned that the QCM-D data (Figure 3(a2)) showed insignificant shifts in $\mathrm{f}$ and $\mathrm{D}$ when $\mathrm{pH}$ is changed from 6 to 3 . However, the AFM force curves indicate relatively shorter-ranged repulsion at $\mathrm{pH}$ 3. As discussed, changing $\mathrm{pH}$ from 6 to 3 should produce minor swelling in the inner and a more considerable collapse in the outer ADA layer. Accordingly, it seems that the collapse in the outer layer has a more significant effect that is detectable by AFM colloidal probe. Further increasing the ionic strength to $100 \mathrm{mM}$ (Figure 4(a3)) results in notable changes in the force profiles. Accordingly, the repulsive force profiles at $\mathrm{pH} 3$ and 6 seem to overlap, suggesting rather similar conformational features under the two conditions, which can be attributed to similar inner film characteristics (Figure 2(a3)), together with a strong screening effect in the outer layer. On the other hand, the repulsive force at $\mathrm{pH} 9$ has become shorter-ranged (screening effect), whereas it is still relatively longer-ranged than at lower $\mathrm{pH}$ values. This observation supports the QCM-D data (Figure 3(a3)) in which minor shifts were found between pH 6 and 3, while a reduced 
swelling was found when changing $\mathrm{pH}$ from 6 to 9. We also notice a general change in the appearance of the force curves from a more "soft tail type" repulsion to a more "strong bulk type" repulsion. For instance, the repulsive force at a separation of $\sim 20-30 \mathrm{~nm}$ at $\mathrm{pH} 9$ is of higher magnitude at an ionic strength of $100 \mathrm{mM}$ compared to at $1 \mathrm{mM}$ even if the absolute range of the repulsion is longer at 1 $\mathrm{mM}$. This observation further supports the idea of electrostatic screening and the collapse of the soft outer part of the film.

According to Figure 4 (panel b), the force-distance curves between two multilayer films capped with $\mathrm{CHI}$ also depend on $\mathrm{pH}$ and ionic strength. For the lowest ionic strength (Figure 4(b1)), the repulsive force is most long-ranged at $\mathrm{pH} 3$, whereas the repulsion is of a rather similar range at $\mathrm{pH} 6$ and $\mathrm{pH}$ 9. These observations follow the trends observed in the QCM-D data (Figure 3(b1)), where no significant swelling was inferred when changing the $\mathrm{pH}$ from 6 to 9, while a significant swelling was observed when changing the $\mathrm{pH}$ from 6 to 3 . Considering that the inner layer shows minor conformational changes between $\mathrm{pH} 3$ and $\mathrm{pH}$ 6, the longer-ranged repulsion at $\mathrm{pH} 3$ implies a more swollen conformation of the outermost CHI layer. The relatively similar force profiles at $\mathrm{pH} 6$ and pH 9 may be attributed to the opposite structural changes in the inner and outer parts of the film. Accordingly, increasing the $\mathrm{pH}$ from 6 to 9 leads to significant swelling in the inner zone, together with the collapse of the outer layer. The combination of these two effects seemingly cancel out each other, as suggested by both QCM-D and AFM measurements. Increasing the ionic strength to $10 \mathrm{mM}$ (Figure 4(b2)) results in shorter-ranged force profiles at all $\mathrm{pH}$ values, which can be correlated to a screening effect on the outer layer. The force profile at $\mathrm{pH} 3$ demonstrates longer-ranged repulsion confirming a swollen outermost CHI later. Moreover, the force profile at $\mathrm{pH} 9$ is more long-ranged than at $\mathrm{pH}$ 6. The outer $\mathrm{CHI}$ layer is expected to collapse when $\mathrm{pH}$ is changed from 6 to 9; therefore, the longer-ranged repulsion at $\mathrm{pH} 9$ may be attributed to the swelling of the inner part of the film (as shown in Figure 2(b3)). These observations are all in agreement with Figure 3(b2), in which swelling 
is predicted under both acidic and alkaline conditions. Increasing the ionic strength to $100 \mathrm{mM}$ (Figure 4(b3)) leads to more short-ranged repulsions at all three $\mathrm{pH}$ values implying a screening effect on the outer CHI layer. The most short-ranged repulsive force is found at $\mathrm{pH} 6$ followed by $\mathrm{pH} 9$ and then $\mathrm{pH}$ 3. Similarly, the longer-ranged repulsion at $\mathrm{pH} 3$ can be attributed to the outer layer contribution, whereas the difference between $\mathrm{pH} 6$ and 9 can be attributed to the more swollen inner layer at $\mathrm{pH} 9$.

Lastly, two important observations must be highlighted in Figure 4. Firstly, the multilayer film capped with ADA shows the longer-ranged repulsion under alkaline condition, whereas the multilayer film capped with CHI exhibits the longer-ranged repulsion under acidic conditions. Secondly, regarding both multilayer systems, increasing the ionic strength, in general, gives rise to shorter-ranged repulsive forces at a given $\mathrm{pH}$ value. These two observations provide convincing proof that AFM colloidal probe, unlike ellipsometry, is more sensitive to the conformational changes in the periphery of the film. Since the swelling behaviors inferred by QCM-D and AFM colloidal probe are mostly identical, one can infer that QCM-D is also quite sensitive on the conformational changes at the film surface.

\section{Zeta potential: electrostatic properties}

In addition to the $\mathrm{pH}$-induced swelling behavior discussed in the previous sections, the overall electrostatic properties of the multilayer films also depend on if the outer layer is CHI or ADA. Figure 5 presents the measured zeta potentials of the multilayer films ( 6 and 7 layers) capped with ADA (Figure 5(a)) or CHI (Figure 5(b)) at different ionic strength and $\mathrm{pH}$ values. For comparison, we have presented the zeta potential of bare silica wafer under the same conditions in the Supporting Information (Figure S6). 

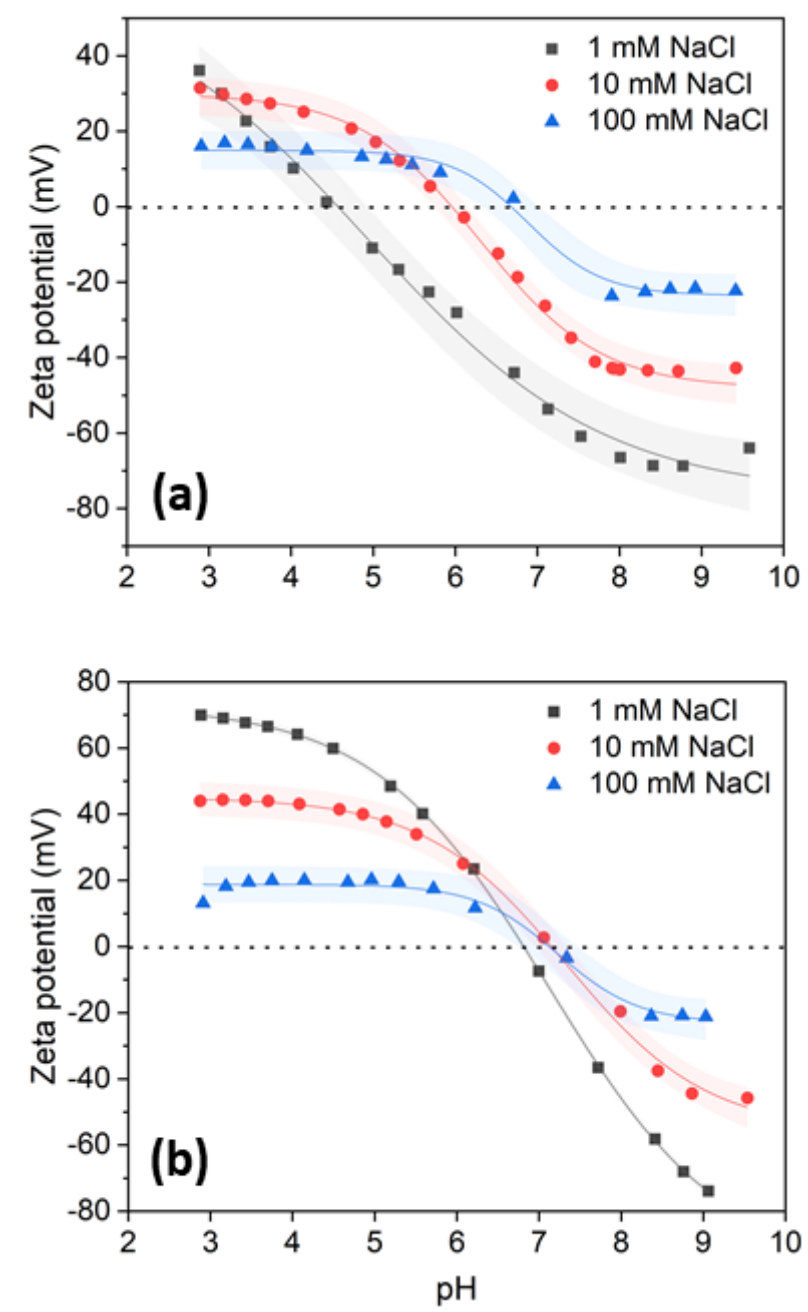

Figure 5 Zeta-potential as a function of $\mathrm{pH}$ value at the different ionic strengths for the multilayer (6 and 7 layers) films capped with $\mathrm{ADA}(\mathrm{a})$ and $\mathrm{CHI}(\mathrm{b})$.

Firstly, regardless if the multilayer film is capped with ADA or $\mathrm{CHI}$, the zeta potential is positive at low $\mathrm{pH}$ and negative at high $\mathrm{pH}$ values. This observation reveals that the electrostatic potential, as seen from the outside of the multilayer film, is not solely controlled by the charge state of the outermost layer, but the charge state of the inner part of the film contributes as well. Secondly, the zeta potential is more positive at low $\mathrm{pH}$ if the outermost layer is $\mathrm{CHI}$ but not significantly more negative at high $\mathrm{pH}$ if the outermost layer is $\mathrm{ADA}$. This suggests that the zeta potential is more sensitive to the overall composition (total amount of charged groups) of the multilayer film than to 
the sign of the charge state of the outermost layer, i.e., when the outermost layer is $\mathrm{CHI}$, the layer contains more $\mathrm{CHI}$ than when the outermost layer is ADA, whereas the layers contain the same amount of ADA in the two cases. Thirdly, independently of if the multilayer film is capped with ADA or $\mathrm{CHI}$, the magnitude of the zeta potential (at all $\mathrm{pH}$ values) decreases with increasing ionic strength. This trend is not specific to the multilayer films but is a general trend for the zeta potential of any charged interface, e.g., a bare silica surface (Supporting Information, Figure S6). This is because the zeta potential is a measure of the effective net charge of the surface (both non-mobile and mobile charges) within the volume given by the slipping plane. Thus, when the double layer is compressed and more ions are available to compensate the non-mobile surface charges, the zeta potential will decrease. Finally, we note that the isoelectric point of the multilayered film appears almost unaffected by the ionic strength when the layer is capped with $\mathrm{CHI}$ while being shifted towards lower $\mathrm{pH}$ values for lower ionic strengths when the layer is capped with ADA.

\section{Discussion}

Thin polymeric films, in general, consist of two distinct zones, i.e., a dense entangled inner zone and a dilute dangling outer zone. Regarding weak polyelectrolyte multilayer films, these two zones also possess distinguished degrees of electrostatic association and complexation. Hence, variations in $\mathrm{pH}$ and ionic strength affect these zones differently. The conventional thin-film analysis methods are each more sensitive to a particular property/region of the polymeric film; therefore, detecting the swelling behavior of thin films can strongly depend on the analysis method. ${ }^{54-56}$ Concerning our work, we considered that ellipsometry is mostly sensitive to the inner polymer-rich part, whereas QCM-D and AFM colloidal probe are more sensitive to the overall film conformation, including the outer layer. The combination of these methods can thus provide an overall picture of the effect of $\mathrm{pH}$ and ionic strength on the CHI/ADA multilayer films (Scheme 1). 
pH 3

$\mathrm{NaCl}$

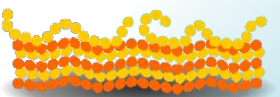

$1 \mathrm{mM}$

$\mathrm{NaCl}$

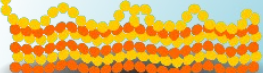

$\mathrm{NaCl}$

$100 \mathrm{mM}$
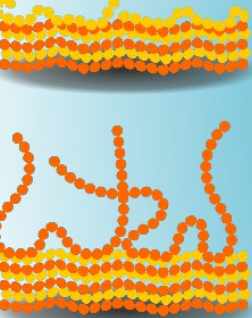

$1 \mathrm{mM}$
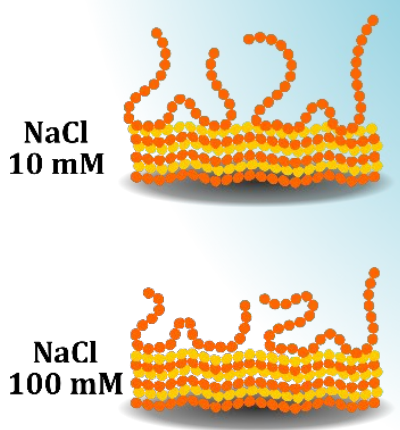

pH 6
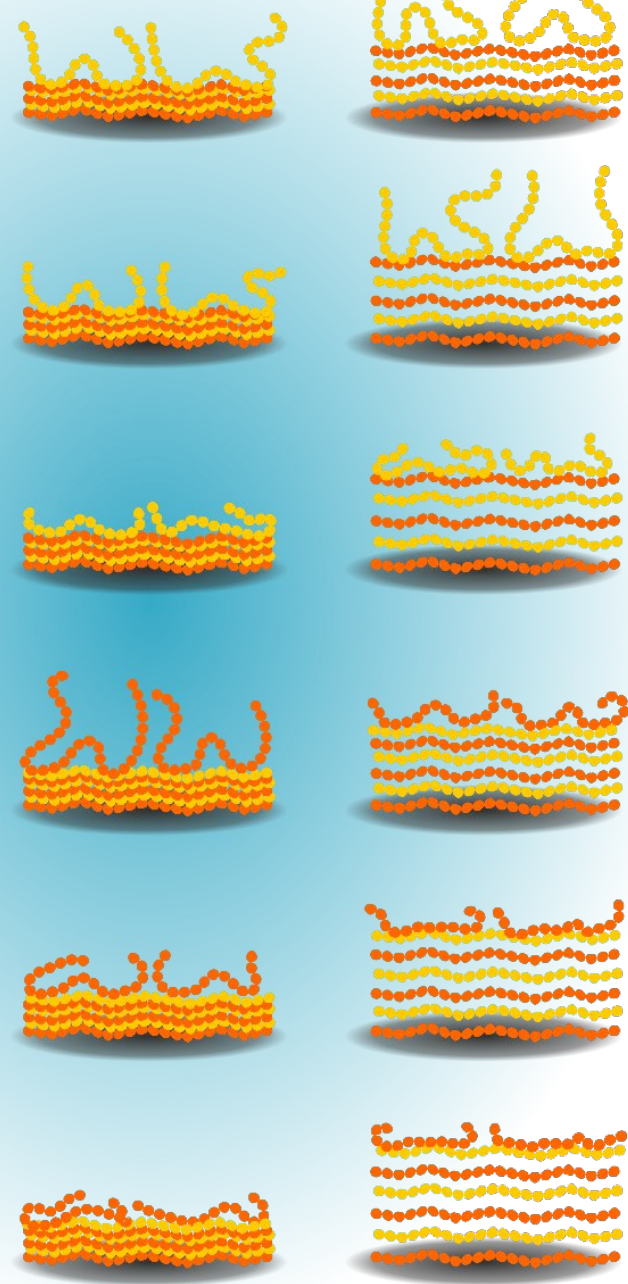

pH 9
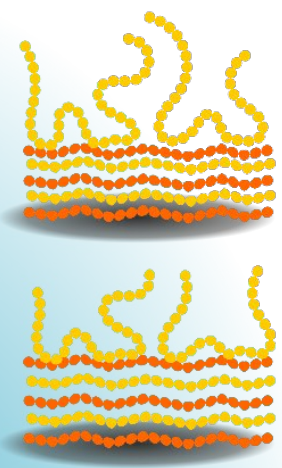

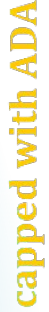
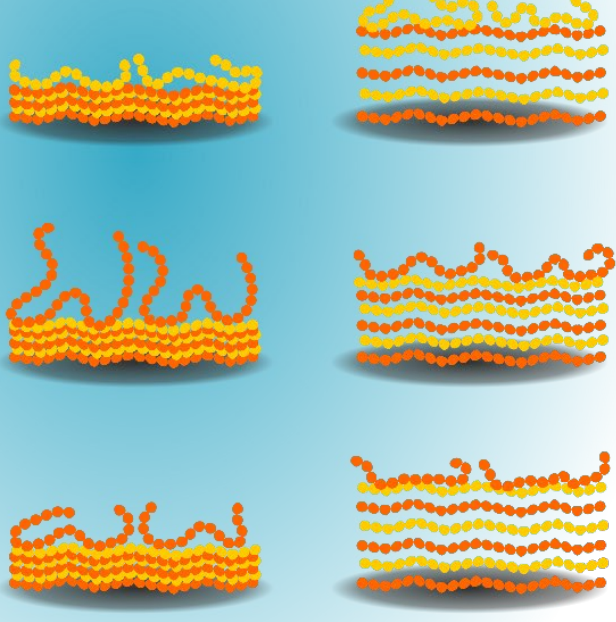

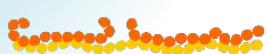

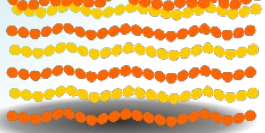

Scheme 1 Schematic illustration of structural conformation and swelling behavior of CHI/ADA multilayer films capped with either ADA (left panel) or CHI (right panel) at different $\mathrm{pH}$ and ionic strengths.

According to the ellipsometry data (Figure 2), the inner part of the film notably swells when $\mathrm{pH}$ is increased from 6 to 9 (strong negative charge imbalance), whereas minor swelling is found when $\mathrm{pH}$ is decreased from 6 to 3 (minor positive charge imbalance). Increasing the ionic strength, in general, gives rise to swelling of the inner part specifically at $\mathrm{pH} 9$, an effect exclusive to crowded weak polyelectrolyte systems such as densely grafted brush systems. However, it has to be considered that 
for the thin films studied in this work (6 and 7 layers), the effect of the inner layer should be relatively weak in general, showing approximate thickness values $\sim 5-15 \mathrm{~nm}$. QCM-D (Figure 3) and AFM colloidal probe (Figure 4) data provide complementary information on the outer part of the films. Accordingly, the multilayer film capped with ADA swells most under alkaline condition, whereas the multilayer film capped with CHI swells most under acidic conditions, a trend that is anticipated for "free" weak polyelectrolyte chains. Considering that the force measurements are performed between two symmetric multilayer films in each case, the steric forces when compressing the films approximately range between 10 to $50 \mathrm{~nm}$. These values are notably larger than the estimated optical thickness values from the ellipsometry measurement (for 6 and 7 layers), affirming the presence of a highly swollen outer layer and different detection mechanisms of the two methods. Increasing the ionic strength apparently imposes a screening effect on the outer layer conformation, an effect expected for isolated weak polyelectrolyte chains. The findings of this study bring up two pivotal points that need extra attention.

First, polyelectrolyte multilayer films demonstrate distinct stimuli-responsiveness and swelling behavior in the inner and outer zones. This has to be considered to avoid misleading conclusions based on different thin-film analysis methods. For example, regarding the multilayer film capped with CHI, the ellipsometry data (Figure 2, panel b) suggests minor swelling under acidic conditions, whereas QCM-D (Figure 3, panel b) and AFM colloidal probe (Figure 4, panel b) both demonstrate considerable swelling. While these results may seem contradictory at first glance, they indeed complement each other to describe the film properties both internally and at its periphery. One has also to note that the thinner the film becomes, the more significant the effect of the swelling at the surface will be, whereas the effect of internal swelling should be more pronounced when discussing relatively thick films. This is of paramount importance, depending on the properties of the multilayer film that are of interest. For instance, the swelling behavior within the film could be of more 
importance when discussing bulk-related properties such as permeability, whereas the swelling behavior of the outermost layer could play a crucial role when surface-related properties such as adhesion and lubrication are under investigation.

Second, while a great number of studies are available on preparation, characterization, and applications of polysaccharide multilayer films, the significant role of the outer layer seems to be neglected. We have herein demonstrated that the $\mathrm{pH}$-responsiveness, salt-responsiveness, swelling behavior, interaction, and electrostatic properties of such multilayer systems substantially depend on the outermost layer. Hence, we suggest that besides fabrication parameters such as $\mathrm{pH}$, ionic strength, and the number of layers, one can tune the interfacial properties of polysaccharide multilayer films by choice of the outermost layer.

\section{Conclusion}

In this work, we investigated the swelling behavior, interaction, and electrostatic properties of $\mathrm{CHI} / \mathrm{ADA}$ multilayer films, capped either with $\mathrm{CHI}$ or with $\mathrm{ADA}$, at different $\mathrm{pH}$ and ionic strengths. The results were explained by discussing the expected structural effects in the inner and outer zones of the multilayer films. The results highlight the importance of the role of the outermost layer on the swelling behavior and interaction of polyelectrolyte multilayer films, which is of great importance in better understanding the underlying mechanisms behind polyelectrolyte multilayer systems as well as the applications of polysaccharide multilayers as functional coatings.

\section{Author information}

Corresponding Author: esth@kemi.dtu.dk, Phone: +45 45252439

\section{Supporting Information}


Calculation of AFM cantilever sensitivity, ellipsometry data analysis and estimated refractive indices, representative AFM force-distance curves, and zeta potential data of bare silica wafer are provided.

\section{Acknowledgments}

J.H. acknowledges a stipend from the Chinese Scholarship Council (CSC), and the support from

Professor Michal Borkovec (Laboratory of Colloid and Surface Chemistry, University of Geneva) regarding the zeta potential experiments.

\section{References}

(1) Dragan, E. S.; Dinu, M. V. Polysaccharides Constructed Hydrogels as Vehicles for Proteins and Peptides. A Review. Carbohydr. Polym. 2019, 225, 115210. https://doi.org/10.1016/j.carbpol.2019.115210.

(2) Schneider, A.; Picart, C.; Senger, B.; Schaaf, P.; Voegel, J.-C.; Frisch, B. Layer-by-Layer Films from Hyaluronan and Amine-Modified Hyaluronan. Langmuir 2007, 23, 2655-2662.

(3) Rinaudo, M. New Way to Crosslink Chitosan in Aqueous Solution. Eur. Polym. J. 2010, 46, 1537-1544. https://doi.org/10.1016/j.eurpolymj.2010.04.012.

(4) Pawar, S. N.; Edgar, K. J. Alginate Derivatization: A Review of Chemistry, Properties and Applications. Biomaterials 2012, 33, 3279-3305. https://doi.org/10.1016/j.biomaterials.2012.01.007.

(5) Sahariah, P.; Masson, M. Antimicrobial Chitosan and Chitosan Derivatives: A Review of the Structure-Activity Relationship. Biomacromolecules 2017. https://doi.org/10.1021/acs.biomac.7b01058.

(6) Kristiansen, K. A.; Potthast, A.; Christensen, B. E. Periodate Oxidation of Polysaccharides for Modification of Chemical and Physical Properties. Carbohydr Res 2010, 345, 1264-1271. https://doi.org/10.1016/j.carres.2010.02.011.

(7) Kristiansen, K. A.; Tomren, H. B.; Christensen, B. E. Periodate Oxidized Alginates: Depolymerization Kinetics. Carbohydr. Polym. 2011, 86, 1595-1601. https://doi.org/10.1016/j.carbpol.2011.06.069.

(8) Gomez, C. G.; Rinaudo, M.; Villar, M. A. Oxidation of Sodium Alginate and Characterization of the Oxidized Derivatives. Carbohydr. Polym. 2007, 67, 296-304. https://doi.org/10.1016/j.carbpol.2006.05.025.

(9) Jia, Y.; Li, J. Molecular Assembly of Schiff Base Interactions: Construction and Application. Chem. Rev. 2014, 115, $1597-1621$. https://doi.org/10.1021/cr400559g.

(10) Tan, H.; Chu, C. R.; Payne, K. A.; Marra, K. G. Injectable in Situ Forming Biodegradable Chitosan-Hyaluronic Acid Based Hydrogels for Cartilage Tissue Engineering. Biomaterials 2009, 30, 2499-2506. https://doi.org/10.1016/j.biomaterials.2008.12.080.

(11) Aston, R.; Wimalaratne, M.; Brock, A.; Lawrie, G.; Grøndahl, L. Interactions between Chitosan and Alginate Dialdehyde Biopolymers and Their Layer-by-Layer Assemblies. Biomacromolecules 2015. https://doi.org/10.1021/acs.biomac.5b00383.

(12) Martins, G. V; Merino, E. G.; Mano, J. F.; Alves, N. M. Crosslink Effect and Albumin Adsorption onto Chitosan/Alginate Multilayered Systems: An in Situ QCM-D Study. Macromol. Biosci. 2010, 10, 1444-1455. https://doi.org/10.1002/mabi.201000193.

(13) Correia, C. R.; Sher, P.; Reis, R. L.; Mano, J. F. Liquified Chitosan-Alginate Multilayer Capsules Incorporating Poly(l-Lactic Acid) Microparticles as Cell Carriers. Soft Matter 2013, 9, 2125-2130. https://doi.org/10.1039/c2sm26784e.

(14) Hillberg, A. L.; Holmes, C. A.; Tabrizian, M. Effect of Genipin Cross-Linking on the Cellular Adhesion Properties of Layer-by-Layer Assembled Polyelectrolyte Films. Biomaterials 2009, 30, 4463-4470. https://doi.org/10.1016/j.biomaterials.2009.05.026.

(15) Silva, J. M.; Caridade, S. G.; Oliveira, N. M.; Reis, R. L.; Mano, J. F. Chitosan-Alginate Multilayered Films with Gradients of Physicochemical Cues. J. Mater. Chem. B 2015, 3, 4555-4568. https://doi.org/10.1039/c5tb00082c.

(16) Huang, J.; Zajforoushan Moghaddam, S.; Thormann, E. Structural Investigation of a Self-Cross-Linked Chitosan/Alginate Dialdehyde Multilayered Film with in Situ QCM-D and Spectroscopic Ellipsometry. ACS Omega 2019, 4 (1), 2019-2029.

https://doi.org/10.1021/acsomega.8b03145. 
(17) Liang, Y.; Liu, W.; Han, B.; Yang, C.; Ma, Q.; Song, F.; Bi, Q. An in Situ Formed Biodegradable Hydrogel for Reconstruction of the Corneal Endothelium. Colloids Surf B Biointerfaces 2011, 82, 1-7. https://doi.org/10.1016/j.colsurfb.2010.07.043.

(18) Chen, F.; Tian, M.; Zhang, D.; Wang, J.; Wang, Q.; Yu, X.; Zhang, X.; Wan, C. Preparation and Characterization of Oxidized Alginate Covalently Cross-Linked Galactosylated Chitosan Scaffold for Liver Tissue Engineering. Mater. Sci. Eng. C 2012, 32, 310-320. https://doi.org/10.1016/j.msec.2011.10.034.

(19) Vieira, E. F. S.; Cestari, A. R.; Airoldi, C.; Loh, W. Polysaccharide-Based Hydrogels Preparation, Characterization, and Drug Interaction Behaviour. Biomacromolecules 208AD, 9, 1195-1199.

(20) Chen, H.; Xing, X.; Tan, H.; Jia, Y.; Zhou, T.; Chen, Y.; Ling, Z.; Hu, X. Covalently Antibacterial Alginate-Chitosan Hydrogel Dressing Integrated Gelatin Microspheres Containing Tetracycline Hydrochloride for Wound Healing. Mater. Sci. Eng. C 2017, 70, 287-295. https://doi.org/10.1016/j.msec.2016.08.086.

(21) Zhao, X.; Chen, S.; Lin, Z.; Du, C. Reactive Electrospinning of Composite Nanofibers of Carboxymethyl Chitosan Cross-Linked by Alginate Dialdehyde with the Aid of Polyethylene Oxide. Carbohydr. Polym. 2016. https://doi.org/10.1016/j.carbpol.2016.04.051.

(22) Wang, Z.; Dong, L.; Han, L.; Wang, K.; Lu, X.; Fang, L.; Qu, S.; Chan, C. W. Self-Assembled Biodegradable Nanoparticles and Polysaccharides as Biomimetic ECM Nanostructures for the Synergistic Effect of RGD and BMP-2 on Bone Formation. Sci. Rep. 2016. https://doi.org/10.1038/srep25090.

(23) Jia, Y.; Fei, J.; Cui, Y.; Yang, Y.; Gao, L.; Li, J. PH-Responsive Polysaccharide Microcapsules through Covalent Bonding Assembly. Chem. Commun. 2011. https://doi.org/10.1039/c0cc03578e.

(24) Mu, B.; Lu, C.; Liu, P. Disintegration-Controllable Stimuli-Responsive Polyelectrolyte Multilayer Microcapsules via Covalent Layer-by-Layer Assembly. Colloids Surfaces B Biointerfaces 2011. https://doi.org/10.1016/j.colsurfb.2010.09.024.

(25) Schlenoff, J. B.; Ly, H.; Li, M. Charge and Mass Balance in Polyelectrolyte Multilayers. J. Am. Chem. Soc. 1998, 120 (30), $7626-7634$. https://doi.org/https://doi.org/10.1021/ja980350+.

(26) Patel, P. A.; Jeon, J.; Mather, P. T.; Dobrynin, A. V. Molecular Dynamics Simulations of Layer-by-Layer Assembly of Polyelectrolytes at Charged Surfaces: Effects of Chain Degree of Polymerization and Fraction of Charged Monomers. Langmuir 2005, 21 (13), 6113-6122. https://doi.org/10.1021/la050432t.

(27) Delcea, M.; Mohwald, H.; Skirtach, A. G. Stimuli-Responsive LbL Capsules and Nanoshells for Drug Delivery. Adv Drug Deliv Rev 2011, 63, 730-747. https://doi.org/10.1016/j.addr.2011.03.010.

(28) Shiratori, S. S.; Rubner, M. F. PH-Dependent Thickness Behavior of Sequentially Adsorbed Layers of Weak Polyelectrolytes. Macromolecules 2000. https://doi.org/10.1021/ma991645q.

(29) Mauser, T.; Déjugnat, C.; Sukhorukov, G. B. Balance of Hydrophobic and Electrostatic Forces in the Ph Response of Weak Polyelectrolyte Capsules. J. Phys. Chem. B 2006. https://doi.org/10.1021/jp063502t.

(30) Itano, K.; Choi, J.; Rubner, M. F. Mechanism of the PH-Induced Discontinuous Swelling/Deswelling Transitions of Poly(Allylamine Hydrochloride)-Containing Polyelectrolyte Multilayer Films. Macromolecules 2005. https://doi.org/10.1021/ma047667g.

(31) Kharlampieva, E.; Sukhishvili, S. A. Ionization and PH Stability of Multilayers Formed by Self-Assembly of Weak Polyelectrolytes. Langmuir 2003. https://doi.org/10.1021/la026546b.

(32) Mauser, T.; Déjugnat, C.; Sukhorukov, G. B. Reversible PH-Dependent Properties of Multilayer Microcapsules Made of Weak Polyelectrolytes. Macromol. Rapid Commun. 2004. https://doi.org/10.1002/marc.200400331.

(33) Burke, S. E.; Barrett, C. J. Swelling Behavior of Hyaluronic Acid/Polyallylamine Hydrochloride Multilayer Films. Biomacromolecules 2005. https://doi.org/10.1021/bm0492834.

(34) Kozlovskaya, V.; Shamaev, A.; Sukhishvili, S. A. Tuning Swelling PH and Permeability of Hydrogel Multilayer Capsules. Soft Matter 2008 https://doi.org/10.1039/b719952j.

(35) Rmaile, H. H.; Schlenoff, J. B. “Internal PKa's” in Polyelectrolyte Multilayers: Coupling Protons and Salt. Langmuir. 2002. https://doi.org/10.1021/la025624s.

(36) Carrillo, J. M. Y.; Dobrynin, A. V. Polyelectrolytes in Salt Solutions: Molecular Dynamics Simulations. Macromolecules 2011. https://doi.org/10.1021/ma2007943.

(37) Volodkin, D.; Von Klitzing, R. Competing Mechanisms in Polyelectrolyte Multilayer Formation and Swelling: Polycation-Polyanion Pairing vs. Polyelectrolyte-Ion Pairing. Current Opinion in Colloid and Interface Science. 2014. https://doi.org/10.1016/j.cocis.2014.01.001.

(38) Han, L.; Mao, Z.; Wuliyasu, H.; Wu, J.; Gong, X.; Yang, Y.; Gao, C. Modulating the Structure and Properties of Poly(Sodium 4Styrenesulfonate)/ Poly(Diallyldimethylammonium Chloride) Multilayers with Concentrated Salt Solutions. Langmuir 2012. https://doi.org/10.1021/la2040533.

(39) Dubas, S. T.; Schlenoff, J. B. Swelling and Smoothing of Polyelectrolyte Multilayers by Salt. Langmuir 2001, 17, 7725-7727.

(40) Wu, T.; Gong, P.; Szleifer, I.; Vlček, P.; Šubr, V.; Genzer, J. Behavior of Surface-Anchored Poly(Acrylic Acid) Brushes with Grafting 
Density Gradients on Solid Substrates: 1. Experiment. Macromolecules 2007. https://doi.org/10.1021/ma0710176.

(41) Gong, P.; Wu, T.; Genzer, J.; Szleifer, I. Behavior of Surface-Anchored Poly (Acrylic Acid) Brushes with Grafting Density Gradients on Solid Substrates: 2. Theory. Macromolecules 2007, 40 (24), 8765-8773.

(42) Drechsler, A.; Elmahdy, M. M.; Uhlmann, P.; Stamm, M. PH and Salt Response of Mixed Brushes Made of Oppositely Charged Polyelectrolytes Studied by in Situ AFM Force Measurements and Imaging. Langmuir 2018. https://doi.org/10.1021/acs.langmuir.8b00498.

(43) Liu, C.; Thormann, E.; Claesson, P. M.; Tyrode, E. Surface Grafted Chitosan Gels. Part I. Molecular Insight into the Formation of Chitosan and Poly(Acrylic Acid) Multilayers. Langmuir 2014. https://doi.org/10.1021/la5013186.

(44) Liu, Y. L.; Su, Y. H.; Lai, J. Y. In Situ Crosslinking of Chitosan and Formation of Chitosan-Silica Hybrid Membranes with Using $\gamma$ Glycidoxypropyltrimethoxysilane as a Crosslinking Agent. Polymer (Guildf). 2004. https://doi.org/10.1016/j.polymer.2004.08.006.

(45) Borch, R. F.; Bernstein, M. D.; Durst, H. D. The Cyanohydridoborate Anion as a Selective Reducing Agent. J. Am. Chem. Soc. 1971. https://doi.org/10.1021/ja00741a013.

(46) Daviero, G. J.; Roberts, P. J. W.; Maile, K. Refractive Index Matching in Large-Scale Stratified Experiments. Exp. Fluids 2001, 31 (2), 119 126. https://doi.org/10.1007/s003480000260.

(47) Sader, J. E.; Chon, J. W. M.; Mulvaney, P. Calibration of Rectangular Atomic Force Microscope Cantilevers. Rev. Sci. Instrum. 1999. https://doi.org/10.1063/1.1150021.

(48) Huang, J.; Liu, X.; Thormann, E. Surface Forces between Highly Charged Cationic Polyelectrolytes Adsorbed to Silica: How Control of PH and the Adsorbed Amount Determines the Net Surface Charge. Langmuir 2018. https://doi.org/10.1021/acs.langmuir.8b00909.

(49) Werner, C.; Körber, H.; Zimmermann, R.; Dukhin, S.; Hans-JörgJacobasch. Extended Electrokinetic Characterization of Flat Solid Surfaces. J. Colloid Interface Sci. 1998, 208, 329-346.

(50) Wang, Q. Z.; Chen, X. G.; Liu, N.; Wang, S. X.; Liu, C. S.; Meng, X. H.; Liu, C. G. Protonation Constants of Chitosan with Different Molecular Weight and Degree of Deacetylation. Carbohydr. Polym. 2006. https://doi.org/10.1016/j.carbpol.2006.01.001.

(51) Pawar, S. N.; Edgar, K. J. Alginate Derivatization: A Review of Chemistry, Properties and Applications. Biomaterials. 2012. https://doi.org/10.1016/j.biomaterials.2012.01.007.

(52) Adam, S.; Koenig, M.; Rodenhausen, K. B.; Eichhorn, K. J.; Oertel, U.; Schubert, M.; Stamm, M.; Uhlmann, P. Quartz Crystal Microbalance with Coupled Spectroscopic Ellipsometry-Study of Temperature-Responsive Polymer Brush Systems. Appl. Surf. Sci. 2017. https://doi.org/10.1016/j.apsusc.2017.02.078.

(53) Ramos, J. J. I.; Moya, S. E. Water Content of Hydrated Polymer Brushes Measured by an in Situ Combination of a Quartz Crystal Microbalance with Dissipation Monitoring and Spectroscopic Ellipsometry. Macromol. Rapid Commun. 2011. https://doi.org/10.1002/marc.201100455.

(54) Richter, R. P.; Brisson, A. R. Following the Formation of Supported Lipid Bilayers on Mica: A Study Combining AFM, QCM-D, and Ellipsometry. Biophys. J. 2005. https://doi.org/10.1529/biophysj.104.053728.

(55) Richter, R. P.; Brisson, A. QCM-D on Mica for Parallel QCM-D - AFM Studies. Langmuir 2004. https://doi.org/10.1021/la049827n.

(56) Murdoch, T. J.; Humphreys, B. A.; Johnson, E. C.; Prescott, S. W.; Nelson, A.; Wanless, E. J.; Webber, G. B. The Role of Copolymer Composition on the Specific Ion and Thermo-Response of Ethylene Glycol-Based Brushes. Polymer (Guildf). 2018.

https://doi.org/10.1016/j.polymer.2018.01.053. 


\section{Graphical abstract}

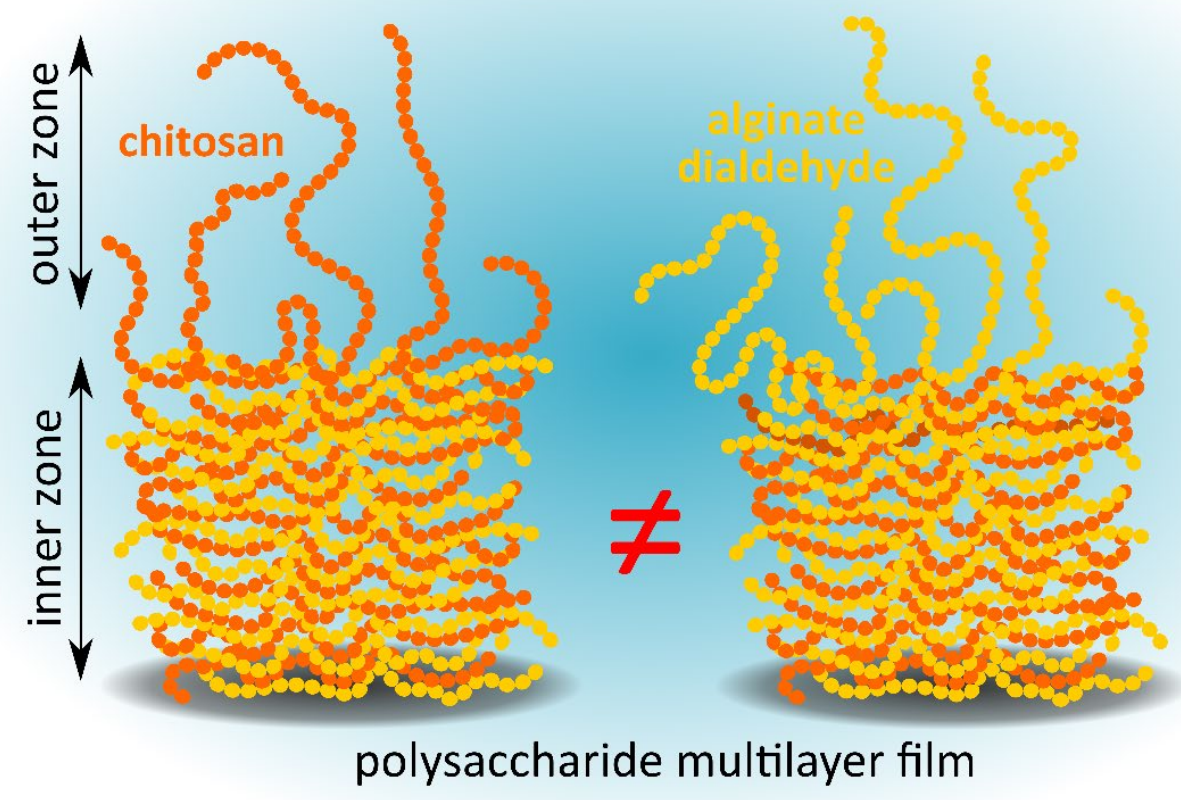

